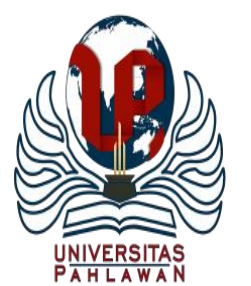

Jurnal Abdidas Volume 1 Nomor 5 Tahun 2020 Halaman 313 - 317

JURNAL ABDIDAS

Community Development Service on Educational and Health Sciences

http://abdidas.org/index.php/abdidas

\title{
Terapi Okupasi Sebagai Sarana Peningkatan Kesehatan Jiwa Penderita Skizofrenia
}

\author{
Sugeng Mashudi ${ }^{1}$, Ririn Nasriati ${ }^{2}$, Eky Octaviani $^{3}$ \\ Progran Studi Ners, Universitas Muhammadiyah Ponorogo ${ }^{1}$ \\ Progran Studi DIII Keperawatan, Universitas Muhammadiyah Ponorogo ${ }^{2,3}$ \\ E-mail : sugengmashudi@umpo.ac.id ${ }^{1}$ yieyien.nasriati@gmail.com ${ }^{2} \underline{\text { ekyvivi80@gmail.com }{ }^{3}}$
}

\begin{abstract}
Abstrak
Permasalahan mitra PKM bermula dengan banyaknya penderita gangguan jiwa yang dirawat yang sudah stabil lebih memilih tinggal di tempat perawatan daripada pulang ke tempat asalnya. Diperlukan upaya positif untuk meningkatkan perbaikan kondisi penderita gangguan jiwa di Paringan. Peran petugas kesehatan dan perangkat desa harus ditingkatkan untuk mencapai perbaikan kondisi penderita gangguan jiwa. Salah satu usaha yang ditawarkan oleh pengusul untuk meningkatkan perbaikan kondisi penderita gangguan jiwa adalah dengan pemberdayaan penderita gangguan jiwa yang sudah stabil (EKS ODGJ). Pemberdayaan penderita belum sepenuhnya diterapkan pada tempat perawatan penderita gangguan jiwa di Paringan. Dua permasalahan yang akan diatasi pada program pengabdian masyarakat ini yaitu: 1) mitra tidak menguasai prinsip pemberdayaan keluarga dengan gangguan jiwa dan 2) penderita dengan gangguan jiwa belum memiliki kegiatan terapi okupasi yang menunjang perbaikan kondisi kejiwaan. Oleh karena itu tim peneliti memberikan solusi atas dua masalah tersebut yaitu focus group discusion prinsip dasar pemberdayaan ODGJ, focus group discusion dampak pemberdayaan terhadap perbaikan kondisi penderita gangguan jiwa, dan pelatihan terapi okupasi untuk penunjang berbaikan kondisi penderita gangguan jiwa.
\end{abstract}

Kata kunci: ODGJ, focus group discusion, Paringan

\section{Abstract}

The problems of PKM Partners started with the number of people with mental disorders who were treated who were already stable preferring to stay in a place of care rather than return to their place of origin. Positive efforts are needed to improve the condition of people with mental disorders in Paringan. The role of health workers and village officials must be increased to achieve improvements in the condition of people with mental disorders. One of the efforts offered by proposers to improve the improvement of the condition of mental disorders is empowering people with mental disorders who are stable. Empowerment of sufferers has not been fully implemented in the care for people with mental disorders in Paringan. Two problems will be resolved in this community service program, namely: 1) partners do not master the principles of empowering families with mental disorders and; 2) Patients with mental disorders do not have occupational therapy activities that support the improvement of their mental condition. Therefore, the research team provided solutions to these two problems, namely: Focus Group Discussion on the basic principles of ODGJ empowerment, Focus Group Discussion on the impact of empowerment on improving the conditions of Mental Disorders, and occupational therapy training to support improving the conditions of Mental Disorders.

Keywords: mental disorders, focus group discusion, Paringan

Copyright (c) 2020 Sugeng Mashudi, Ririn Nasriati, Eky Octaviani

$\triangle$ Corresponding author

Address : FIK UMPonorogo Jl. Budi Utomo 10 Ponorogo

ISSN 2721-9224 (Media Cetak)

Email : sugengmashudi@umpo.ac.id

ISSN 2721-9216 (Media Online)

Phone : 081803173855

DOI : https://doi.org/10.31004/abdidas.v1i5.62 


\section{PENDAHULUAN}

Skizofrenia merupakan gangguan jiwa berat dengan berbagai macam gejala (halusinasi, waham, gangguan perilaku, gangguan berbicara, dan penurunan kemauan) dan mempengaruhi berbagai aspek kehidupan keluarga dan penderita (Marco M Picchioni, 2007). Dampak yang ditimbulkan gangguan jiwa berat pada keluarga cukup kompleks. Berbagai faktor yang berkontribusi terhadap kompleksitas ini diantaranya kurangnya informasi tentang diagnosis penyakit oleh penyedia layanan kesehatan, reaksi keluarga terhadap diagnosis pasien, berkurangnya interaksi antara keluarga dan pasien, dan strategi coping keluarga yang tidak efektif sehingga mempengaruhi tingkat gejala dan peningkatan kekambuhan (Caqueo-Urízar et al., 2017).

Sebanyak 50-90\% pasien skizofrenia hidup dengan keluarganya (Von Kardorff et al., 2016a). Diperkirakan 43,5 juta orang Amerika memerlukan pengasuh dengan durasi 19 jam per minggu (Greenwald, 2009). Data WHO (2018) sebanyak 21 juta jiwa menderita Skizofrenia. Sekitar $1 \%$ populasi di UK merupakan penderita Skizofrenia (Smith, 2015). Iran sekitar 7 juta penduduk menderita Skizofrenia (Von Kardorff et al., 2016b). Data riskesdas 2018 di Indonesia menunjukkan peningkatan proporsi rumah tangga gangguan Skizofrenia sebesar 7 per mil yang sebelumnya hanya 1,7 permil, lebih khusus di daerah provinsi Jawa Timur menunjukkan tahun 2013 hanya 2,2 permil, 2018 merangkak naik menjadi 5 permil (Riskesdas, 2013; 2018). Secara umum angka kejadian yang sama terjadi di Ponorogo, sebanyak 1.321 dari 600.336 penduduk usia produktif mengalami Skizofrenia (Nasriati, 2017). Namun demikian, prevalensi di Desa Paringan dan Dukuh Mirah ditemukan angka yang lebih tinggi. Prevalensi Skizofrenia di Desa Paringan sebesar 11,2 per mil (Mashudi et al., 2016). Sedangkan prevalensi Skizofrenia di Dukuh Mirah sebesar 21,7 per mil (data puskesmas Sampung 2017).

Permasalahan mitra PKM bermula dengan banyaknya penderita gangguan jiwa yang dirawat yang sudah stabil lebih memilih tinggal di tempat perawatan daripada pulang ke tempat asalnya. Berdasarkan keterangan dari Kapala Desa, bahwa Desa Paringan merupakan desa dengan penduduk yang mengalami gangguan jiwa yang cukup banyak. Meskipun saat ini telah didirikan puskesmas Jiwa Paringan, namun kasus gangguan jiwa belum bisa tertangani secara maksmal. Diperlukan upaya positif untuk meningkatkan perbaikan kondisi penderita gangguan jiwa di Paringan. Peran petugas kesehatan dan perangkat desa harus ditingkatkan untuk mencapai perbaikan kondisi penderita gangguan jiwa. Salah satu usaha yang ditawarkan oleh pengusul untuk meningkatkan perbaikan kondisi penderita gangguan jiwa adalah dengan pemberdayaan penderita gangguan jiwa yang sudah stabil (EKS ODGJ). Selama ini, penanganan gangguan jiwa oleh Puskesmas pembantu Paringan belum ada usaha-usaha yang positif untuk melibatkan penderita secara maksimal dalam peningkatan perbaikan kondisi penderita gangguan jiwa. Pemberdayaan penderita belum sepenuhnya diterapkan pada tempat perawatan penderita gangguan jiwa di Paringan. Setelah dilakukan 
diskusi/musyawarah dengan mitra, maka permasalahan mitra secara umum adalah: 1) mitra belum menguasai prinsip dasar pemberdayaan penderita gangguan jiwa; 2) penderita dengan gangguan jiwa belum memiliki kegiatan terapi okupasi yang menunjang perbaikan kondisi kejiwaan; 4) peralatan pendukung terapi okupasi gangguan jiwa masih minim 5) lingkungan ruang rawat inap belum di optimalkan.

Berdasarkan wawancara tim pengabdian menyimpulkan bahwa terdapat dua masalah yang akan diatasi yaitu: 1) mitra tidak menguasai prinsip pemberdayaan keluarga dengan gangguan jiwa dan; 2) penderita dengan gangguan jiwa belum memiliki kegiatan terapi okupasi yang menunjang perbaikan kondisi kejiwaan. Oleh karena itu tim peneliti memberikan solusi atas dua masalah tersebut yaitu focus group discusion prinsip dasar pemberdayaan ODGJ, focus group discusion dampak pemberdayaan terhadap perbaikan kondisi penderita gangguan jiwa, dan pelatihan terapi okupasi untuk penunjang berbaikan kondisi penderita gangguan jiwa.

\section{METODE}

Permasalahan yang dialami mitra secara runtut diatasi menjadi 3 hal kegiatan yaitu fokus group discussion, demonsrasi dan praktik. Focus Group Discusion prinsip dasar pemberdayaan ODGJ, Focus Group Discusion dampak pemberdayaan terhadap perbaikan kondisi penderita gangguan jiwa, dan pelatihan terapi okupasi untuk penunjang berbaikan kondisi penderita gangguan jiwa.

\section{HASIL DAN PEMBAHASAN}

Focus group discusion tentang prinsip dasar pemberdayaan ODGJ pada pengelola dilaksanakan di Puskesmas pembantu paringan dengan dihadiri oleh staf puskesmas, keluarga serta penderita gangguan jiwa. Waktu yang dibutuhkan untuk FGD selama 3x60 menit dengan materi prinsip dasar pemberdayaan ODGJ. Fasilitator mempresentasikan PPT prinsip dasar pemberdayaan, kemudian dilakukan diskusi terfokus, kegiatan dianggap cukup jika tidak ada hal yang dipertanyakan/dipersoalkan oleh peserta. Indikator keberhasilan program menunjukkan bahwa peserta/keluarga penderita gangguan jiwa memahami manfaat prinsip dasar pemberdayaan.

Focus group discusion tentang dampak pemberdayaan Eks ODGJ terhadap perbaikan kondisi Penderita Gangguan Jiwa dilakukan di PKM Paringan. Waktu yang dibutuhkan FGD selama 3x60 menit. Materi yang disajikan adalah perbaikan kondisi penderita gangguan jiwa dengan pemberdayaan. Fasilitator mempresentasikan PPT dampak pemberdayaan terhadap perbaikan kondisi penderita gangguan jiwa, kemudian dilakukan diskusi terfokus, kegiatan dianggap cukup jika tidak ada hal yang dipertanyakan/dipersoalkan oleh peserta. Indikator keberhasilan program menunjukkan bahwa peserta memahami bentuk perbaikan penderita gangguan jiwa.

Terapi okupasi bertempat di rumah penderita gangguan jiwa, PKM Paringan, serta Rumah terapi Margo Widodo. Kegiatan ini dipantau selama satu bulan. Kegiatan yang dilakukan berupa menanam sayuran di polibek serta beternak ayam. Indikator keberhasilan berupa 
penurunan tingkat kekambuhan gangguan jiwa serta aktivitas positif penderita gangguan jiwa yang meningkat.

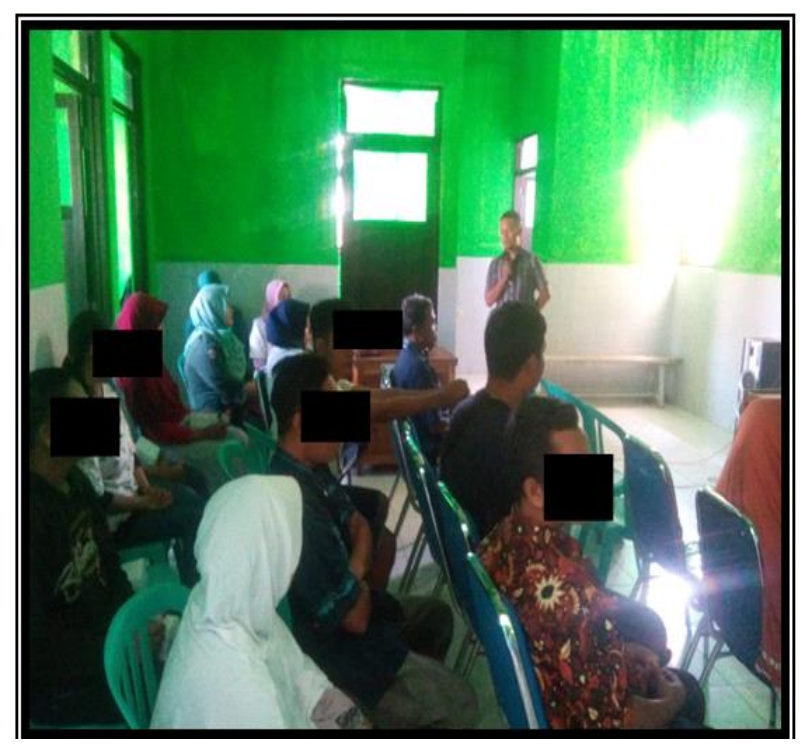

Gambar 1. FGD Tim Pengabdian dengan Puskesmas dan Keluarga ODGJ

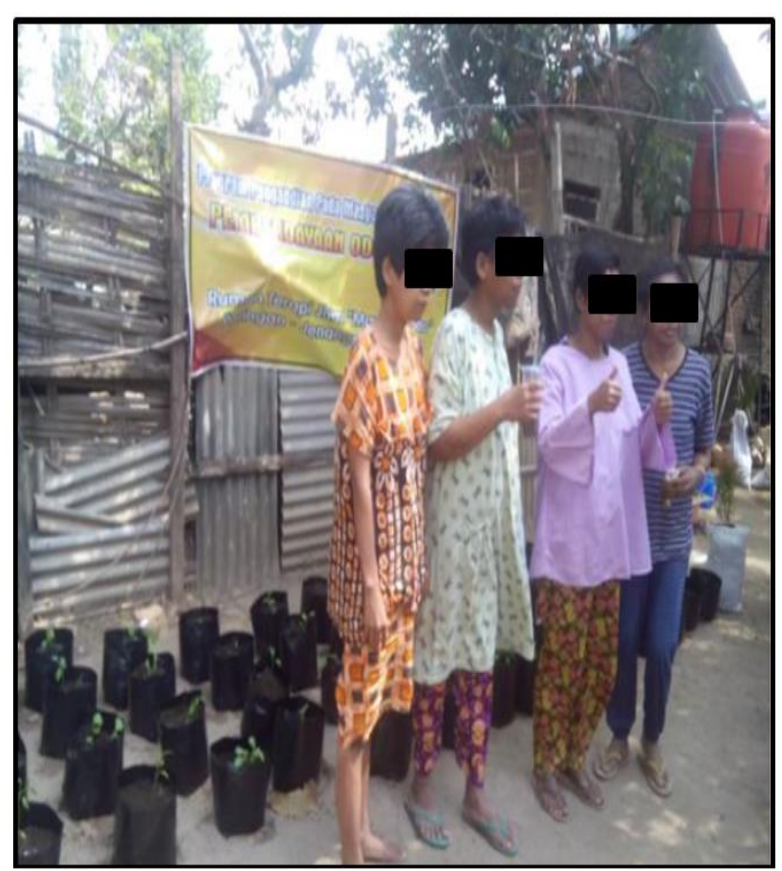

Gambar 2. Terapi Okupasi pada ODGJ

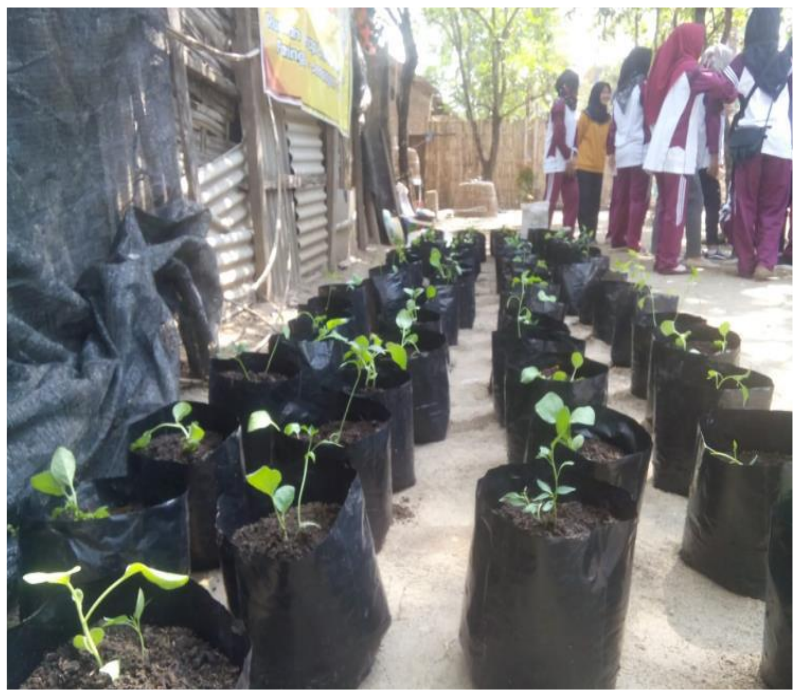

Gambar 3. Hasil Usaha Terapi Okupasi pada ODGJ

\section{SIMPULAN}

Hasil pengabdian masyarakat ini dapat menjadi sumber informasi bagi petugas kesehatan terutama perawat dalam memberikan asuhan keperawatan pada tatanan komunitas terkait terapi okupasi bagi penderita Skizofrenia. Sebaiknya kegiatan ini dilakukan secara rutin oleh petugas kesehatan sebagai tindak lanjut bagi masyarakat dalam rangka meningkatkan derajat kesehatan keluarga serta penderita Skizofrenia yang optimal.

\section{UCAPAN TERIMA KASIH}

Terima kasih kami ucapkan kepada Puskesmas Pembantu Paringan, Rumah terapi Margo Widodo Paringan dan Universitas Muhammadiyah Ponorogo atas dukungan dan kerjasama selama pelaksanaan pengabdian masyarakat.

\section{DAFTAR PUSTAKA}

Caqueo-Urízar, A., Alessandrini, M., Urzúa, A., Zendjidjian, X., Boyer, L., \& Williams, D. R. 
(2017). Caregiver's quality of life and its positive impact on symptomatology and quality of life of patients with schizophrenia. Health and Quality of Life Outcomes, 15(1), 1-9. $\quad$ https://doi.org/10.1186/s12955-0170652-6

Greenwald, M. (2009). Caregiving in the U.S. 2009. November, 1-79. http://assets.aarp.org/rgcenter/il/caregiving_0 9_fr.pdf\%5Cnpapers2://publication/uuid/F95 CD001-E1F8-4FDB-87B3-41477D77C8B5

Marco M Picchioni, R. M. M. (2007). Schizophrenia. BMJ, 335(July), 102-113. https://doi.org/10.1201/9781315380612

Mashudi, S., Widiyahseno, Ba., \& Priyoto. (2016). Model Kampung Gila Ponorogo (1st ed.).

Smith, G. (2015). Skizophrenia. In I. Peate (Ed.), Mental Health Nursing at a Glance (First Edit, p. 34). John Wiley\&Sons, Ltd.

Von Kardorff, E., Soltaninejad, A., Kamali, M., \& Eslami Shahrbabaki, M. (2016a). Family caregiver burden in mental illnesses: The case of affective disorders and schizophrenia - a qualitative exploratory study. Nordic Journal of Psychiatry, 70(4), 248-254. https://doi.org/10.3109/08039488.2015.1084 372

Von Kardorff, E., Soltaninejad, A., Kamali, M., \& Eslami Shahrbabaki, M. (2016b). Family caregiver burden in mental illnesses: The case of affective disorders and schizophrenia - A qualitative exploratory study. Nordic Journal of Psychiatry, 70(4), 248-254. https://doi.org/10.3109/08039488.2015.1084 372 